\title{
The Determinants of Citizens' Satisfaction of E-Government: An Empirical Study in Vietnam
}

\author{
Thuy Thu NGUYEN ${ }^{1}$, Duc Manh PHAN ${ }^{2}$, Anh Ha LE ${ }^{3}$, Lan Thi Ngoc NGUYEN ${ }^{4}$
}

Received: June 05, 2020 Revised: June 21, 2020 Accepted: July 09, 2020

\begin{abstract}
This research aims to identify the determinants of e-government satisfaction in Hanoi, Vietnam, and assess their impact. To collect data, we conducted an online questionnaire with citizens living in Hanoi in a time span of five weeks. We received 1,107 responses, divided into three groups: unaware, known, but not used, and used e-government. After leveraging past studies on satisfaction in different contexts, we arrived at six external variables that are of particular relevance to e-government satisfaction (i.e., efficiency, trust, reliability, convenience, citizen support, and transparency) as well as four control variables (i.e., age, gender, education level, and Internet frequency). We then applied both SPSS 22 and STATA 2016 to process and analyze the collected data and found that, while almost all external variables are statistically significant, all four control variables are not. Apart from convenience and trust, four factors - efficiency, reliability, citizens support, transparency - are important measures of system quality, information quality, service quality and relative benefits of e-government, which in turn positively and significantly impact citizens' satisfaction with the online public services. Furthermore, the efficiency variable has the most influence on customer satisfaction, and the level of impact on the dependent variable decreases in the following order: citizen support, reliability and transparency.
\end{abstract}

Keywords: E-government, Customer Satisfaction, Vietnam

JEL Classification Code: B16, M10, M31

\section{Introduction}

The rapid evolution of information technology and related services has brought a significant improvement in social standards, especially in satisfying individual demands.

${ }^{1}$ First Author. NEU Business School, National Economics University, Vietnam. Email: ntthuy6199@gmail.com

${ }^{2}$ NEU Business School, National Economics University, Vietnam. Email: pmhduc1999@gmail.com

${ }^{3}$ School of Mathematics, Simon Fraser University, British Columbia, Canada. Email: haanhle.hn@gmail.com

${ }^{4}$ Corresponding Author. School of Accounting and Auditing, Van Lang University, Vietnam [Postal Address: 45 Nguyen Khac Nhu Street, Co Giang Ward, District 1, Ho Chi Minh City, 700000, Vietnam] Email: nguyenthingoclan@vanlanguni.edu.vn ; nguyenthingoclan29071997@gmail.com

(c) Copyright: The Author(s)

This is an Open Access article distributed under the terms of the Creative Commons Attribution Non-Commercial License (http://Creativecommons.org/licenses/by-nc/4.0/) which permits unrestricted noncommercial use, distribution, and reproduction in any medium, provided the original work is properly cited.
Along with this inevitable technological development trend, governments have digitized public services, in other words, developed e-government to tackle problems related to the current managerial system before upgrading new services to meet the society contentment (Giao, 2020). Currently, countries around the globe are constantly striving to improve e-government and provide online public services, according to the latest report on e-government from the United Nations (2018). Specifically, the 2018 survey highlighted a positive global trend towards a higher level of e-government development. In 2018, 40 countries achieved e-government development index (EGDI) at the level of "Very high", compared to only 10 countries in 2003. In addition, the average EGDI of countries around the world has increased from 0.47 in 2014 to 0.55 in 2018, which means that overall e-government development has increased across regions. This shows that, globally, the improvement of e-government and the provision of online public services have made certain progress. This is also the situation in Vietnam since the country has continuously promoted the development of the e-government system. Specifically, it has been demonstrated 
that Vietnam's e-government development index (EGDI) has constantly increased, from 0.47 in 2014 to 0.59 in 2018, bringing Vietnam up from 99th in 2014 to the rank of 88/193 countries in 2018, ranking 6th among 11 countries in the ASEAN region (United Nations, 2018). However, although Vietnam has made certain progress, the pace is relatively slow, especially compared to other ASEAN countries. Furthermore, the quality of online public service provision is limited and inconvenient for users, manifested by the availability of many online public services, but the actual number of services used is still limited.

To improve the situation, in other words, to increase the rate of online usage of public services, it is vital to understand what e-government is and what determines its success. E-government is a general term for web-based services from government agencies. In recent years, although many e-government concepts have been put forward, all are aimed at using information technology to improve the effectiveness of the Government. With this topic, the concept of e-government is proposed as "the application of information technology to improve the provision of government services to citizens, thereby improving people's satisfaction with the services provided by the Government". A valuable insight into the performance of the information system, yielded by DeLone and McLean (2003), has shown that user satisfaction is one of the key factors in determining the effectiveness of the system implementation. As users should be placed at the heart of the development and delivery of electronic public services since their satisfaction can have a pivotal impact on the large-scale adoption of other use of electronic public services (Verdegem \& Verleye, 2009), the investigation into citizens, which are the main users of the systems, is crucial (Gilbert, Balestrini, \& Littleboy, 2004).

As a result, numerous studies about e-government satisfaction were conducted, from the effect of satisfaction on different aspects (Welch, 2004) to determinants of e-government satisfaction (Papadomichelaki \& Mentzas, 2012; Verdegem \& Verleye, 2009). In this field, many researchers tried to address the issue through both theoretical and empirical sides. For example, in Venkatesh, Thong, Chan, $\mathrm{Hu}$, and Brown (2011), citizens' intentions of using e-government are predicted by the quality of information and the channel characteristic, which lead to citizens' satisfaction. Or according to Bhattacharya, Gulla, \& Gupta (2012), improving the quality of online services base on the needs and expectations of citizen can act as a positive trigger for e-government adoption. However, most of the previous studies are based in developed countries, thus can barely appropriate to apply in developing countries, including Vietnam. Due to the distinction of cultural, social and economic attributes, there is a substantial gap between the two parts of the world in this field of study. Additionally, in Vietnam, there were no previous studies about what factors driving the satisfaction with e-government comprehensively from the Vietnamese citizens' perspective. In short, the mentioned issue of Vietnamese e-government has not been fully discovered.

Therefore, this article is conducted to tackle the problem by measuring the level of satisfaction of citizens and examining its determinants with respect to electronic government services in Hanoi, Vietnam. The research model is mainly based on the revised e-GovQual model developed by Papadomichelaki and Mentzas (2012) since this is an updated model that was constructed exclusively to measure satisfaction with the electronic government system and was tested on a large-scale sample. Our study was carried out as a quantitative research with a considerable sample size of 1,100 respondents.

In the following sections, both theoretical and empirical studies are used to discuss satisfaction definitions and its determinants in the field of e-government. Next, the development of the research model and measurements are presented, followed by the validation of the measurement tool. Finally, conclusions and recommendations from the research are drawn.

\section{Literature Review}

There is no consensual definition of e-government citizen satisfaction. Researchers conceptualized e-government citizen satisfaction as a service providercustomer relationship in which the government is the service provider and citizens are the customers. Therefore, e-government citizen satisfaction can also be considered as customer satisfaction. Cardozo (1965) suggested customer satisfaction is not just an evaluation of a product but also the experience surrounding the purchase of the product. In other words, customer satisfaction is built in their trust and implied as a process of evaluating product procurement experience (Usman, 2015). Oliver (1977) expanded Cardozo's concept of product acquisition experience, postulating that such evaluation is the result of the differences between expectations and perceptions of service performance. That is to suggest, higher perceptions of performance compared to pre-consumption expectations lead to higher satisfaction and vice versa. Apart from evaluations of service, satisfaction also depends on an individual's comparison of net benefits against other customers- if the comparison is perceived to be fair then customers are satisfied (Seetharaman et al., 2017). On the other hand, researchers focus on satisfaction as an outcome of the evaluation process. Specifically, satisfaction can be an emotional response when experiencing consumption (Westbrook \& Reilly, 1983), a response to the fulfillment of desires and needs (Rust \& Oliver, 1994), or evaluative response (Day, 1984). 
Even though disagreement on a global definition of customer satisfaction persists, that didn't stop researchers from operationalizing customer satisfaction within the domain of e-government, albeit making measurement of e-government citizen satisfaction and comparison of papers more context-dependent. Welch (2004) is one of the first studies to measure e-government satisfaction related to government trust. Specifically, he defined e-government satisfaction as "overall rating of the effect (positive to negative) of e-government on the operation of government" which includes: (1) transaction satisfaction, (2) transparency satisfaction, and (3) interactivity satisfaction. Unfortunately, to the best of our knowledge, there is no other e-government study that gives out a definition of e-government satisfaction. Excluding Welch's, other research on satisfaction with e-government services measure satisfaction as it is, which means asking: "How are you satisfied with the service?" questions. Part of the reason lies in the fact that satisfaction is an elusive, "you know it when you see it" concept (Oliver, 1977). Nevertheless, many researchers have adopted this mantra and either left measurement of satisfaction to the respondents (Verdegem \& Verleye, 2009), or only focused on determinants of satisfaction (Chan et al., 2010).

About the determinants of customer satisfaction, Szymanski and Henard (2001) found that, not only is the performance of service a major component along with expectations in the expectation-confirmation paradigm proposed by Oliver (1977) mentioned above, but also a significant direct predictor of satisfaction. In general, researchers of e-government agree on three major groups of determinants, drawn from information systems literature: (1) system quality factors, which represent the quality of information processing (ease of use, website design, reliability and interactivity) (Santos, 2003), (Delone \& McLean, 2003), (2) information quality factors measure the perceived value of the information produced by the website which includes (security, content, accuracy) (Parasuraman, 1991; Papadomichelaki \& Mentzas, 2012), and (3) service quality factors represent overall customer evaluation of service delivery's quality including SERVQUAL constructs (Parasuraman, 1991) as well as trust, support, and efficiency (Warkentin, Gefen, Pavlou, \& Rose, 2002).

Regarding system quality factors, many pieces of research showed the positive relationship between website design and satisfaction. This is because website-oriented variables are the primary factors in measuring perceived performance (Lin, 2007, p. 2). Additionally, citizens are also more satisfied when they do not have to expend effort into figuring out the website navigation, thus improving website quality also means having higher quality for website structure, search engine as well as set-up links. Specifically, with e-government where citizens want reliable and easy access to services, good search functions and website structure greatly reduce steps taken to find and fill out forms, thus enhancing their experience. Hujran, Aloudat, and Altarawneh (2013) also showed ease-of-use has a significant impact on citizen satisfaction.

On the other hand, information quality shows a comparatively positive relationship with satisfaction. Livari (2005) illustrated that information quality significantly affects an individual's perception of the usefulness of information systems. And Delone and McLean (2003) proved that the quality of information influences net benefits experienced by the users. As defined by Delone and McLean, net benefits form several measures as represented by the impact information systems have on users like individual impact, organizational impact, etc., as befitting the purpose of the research. In our case, information quality's impact on individual citizens is an important indicator of satisfaction. Specifically, Zhang, Keeling, and Pavur (2000) concluded that having correct, easy-to-understand information is vital to meet the needs and expectations of information systems' users. Another aspect of online services, security, is also a key component of information quality. A study by Miyazaki and Fernandez (2001) showed that the protection of information is a major obstacle in adopting online services, as users concern whether their information is more exposed to malicious use in the online environment, among other risks. Since citizens rely on e-government website to show them the correct online forms as well as protect sensitive information, we expect information quality to have an even bigger impact on citizen's e-government satisfaction.

Finally, service quality plays a critical role to support a smooth e-government experience an improve satisfaction. Parasuraman (1991) conceptualized service quality as the gap between expectations and perceptions of service's performance, similar to the conceptualization of satisfaction of Oliver (1977). Although there was a debate on whether service quality is the determinant of satisfaction or vice versa, studies often consider service quality as the indicator of satisfaction(Mosahab, Mahamad, \& Ramayah, 2010). Delone and McLean (2003) acknowledged the importance of service quality in the measurement of information systems success, thus many studies have attempted to incorporate models from service quality literature, most notably the SERVQUAL 5-constructs: tangibles, reliability, responsiveness, assurance, and empathy (Pitt, Watson, \& Kavan, 1995). Even though SERVQUAL is criticized for its unsuitability in information systems context (Van Dyke, Kappelman, \& Prybutok, 1997), many papers found its constructs are useful indicators for information systems providers to identify areas of improvement for service quality (Jiang, Klein, \& Crampton, 2000). Apart from SERVQUAL dimensions, early contribution by Warkentin et al. (2002) identified trust as another factor of e-government services delivery quality. Carter and Bélanger (2005) expanded the trust dimension 
into two different constructs: trust in technology, and trust in government and their results emphasized trustworthiness as the most difficult and vital area to improve as to facilitate e-government use. When examined the success of the online tax filing system, Chen, Jubilado, Capistrano, \& Yen (2015) found trust in government influences trust in e-government websites, which in turn affects how citizens perceive the quality of information posted on the website.

Two notable contributions to the body of e-government satisfaction research in Vietnam of Loan (2020) on online tax filing system and Nguyen (2017) on automated customs clearance in Danang. Both studies were conducted using 5-point Likert-scale questionnaire with regards to businesses in Vietnam. Overall, Nguyen (2017)'s regression equation explains $65.3 \%$ of the variance in the model, suggesting that the model is well fitted to explain the satisfaction of the automated customs clearance system. In contrast, Loan's model only explains $59.6 \%$ of the total variance, thus we can deduce that Loan's model has less predictive power compared to Nguyen (2017)'s. According to Loan (2020), the satisfaction with online tax filing system is determined by six variables: Efficiency, Convenience, Ease-of-use, Information security, Trust, and System readiness. All six hypotheses are proven to have a significant influence on the business satisfaction of online tax filing system at the 95\% confidence level. Meanwhile, Nguyen (2017)'s study on business satisfaction with automated clearance systems is determined by the quality of service which in turn is determined by seven variables: System quality, Trust, Ability to deliver services, Safety, Empathy, Administrative procedure, and Control and feedback mechanism. However, three variables were found not to have a significant impact on business satisfaction including Trust, Safety, and Administrative procedure. Since government and citizen's business relationship can be conceptualized as a service provider-customer relationship, the results are also of relevance to citizen satisfaction research.

\section{Methodology}

\subsection{Hypothesis}

For the purposes of this study, efficiency construct refers to the information quality and the ease of using the government websites, which in accordance with the definition provided by Papadomichelaki and Mentzas (2012). While ease of use captures the idea of the e-government website is user-friendly and requires low effort to use the system, information quality covers the accuracy and freshness of information delivered by the government and both of them are the satisfaction drivers of self-service technology (Meuter, Ostrom, Roundtree, \& Bitner, 2000). The rationale is that, regarding ease of use, users express great concern about complexity and effort when carrying out the online services, and a poorly designed website that is difficult to use can cause frustration for them (Meuter, Ostrom, Roundtree, $\&$ Bitner, 2000). Thus, when a higher level of ease of use is perceived, the greater the likelihood of citizens are going to be satisfied (Papadomichelaki \& Mentzas, 2012).

H1: Efficiency has a positive influence on citizens' satisfaction with e-government.

Papadomichelaki and Mentzas (2012) defined trust as "the citizen's confidence towards the website concerning freedom from risk of danger or doubt during the e-service process". Not only does trust take part in the forming of expectations, which directly affect satisfaction, but also inspires confidence that the government will act to safeguard their citizens' privacy. Carter and Bélanger (2005) similarly showed that in the absence of physical presence between citizens and the government, citizens are more likely to realize e-government's benefits if they are confident their information is not used maliciously by the government, especially sensitive information such as home address, phone number, etc., that some services require (Welch, 2004; Chan et al., 2010).

H2: Trust has a positive influence on citizens'satisfaction with e-government.

As shown in previous research, Papadomichelaki and Mentzas (2012) described reliability as "the citizen's confidence towards the e-government site concerning correct and on-time delivery of the service". E-government promise to deliver quick access to public services compared to traditional bureaucracy, and as such citizens expect services to be available not just anywhere, but also anytime. In fact, reliability is an essential component of the performanceexpectation model SERVQUAL (Parasuraman et al., 1991) that directly contributes to satisfaction. The results of the model indicated that customers expect the service to be available at any time that was promised and will provide the service correctly the first time. Therefore, we expect that a well-functioning e-government site to have a great impact on citizens' satisfaction.

H3: Reliability has a positive influence on citizens' satisfaction with e-government.

Citizens Support is defined as the assistance delivered by the government in the e-government websites. This dimension consists of prompt replies to citizens' inquiries (responsiveness), knowledge to answer users' questions, ability to convey trust and confidence (assurance) and showing sincere interest (empathy) (Delone \& McLean, 
2003; Papadomichelaki \& Mentzas, 2012). Although no direct human interaction is available in the online public service process, there is still indirect contact between officials and citizens, such as the process of providing and responding to citizens' reflections and complaints. It was confirmed by DeLone and McLean (2003) that for the case of e-commerce, overall support given by the service provider plays a more crucial role than previously as poor user support will lead to unpleasant experience of customers. Likewise, the significant impact of the support mechanism on citizens' satisfaction was revealed in some past studies regarding e-government services (Papadomichelaki \& Mentzas, 2012). Citizens Support, therefore, is assumed to have a positive influence on citizens' satisfaction.

H4: Citizens support has a positive influence on citizens' satisfaction with e-government.

In addition to the service-quality dimensions of electronic government mentioned, the perceived relative benefits that users can gain by using online services compared to traditional ones are also determinants of their satisfaction. Among those advantages, convenience was identified to be a significant factor affecting the satisfaction of consumers with the services (Collier \& Sherrell, 2010; Meuter et al., 2000). Like the e-services studied by previous research, the idea of an online public service system, which offers unlimited service hours and enables citizens to consume it anywhere is preferred. Consistent with a study of Gilbert et al. (2004), in this research, convenience refers to the availability of the electronic services, which allow citizens to access it anytime and anywhere. Thanks to the presence of e-government, even an individual having a hectic schedule can easily find time to carry out the necessary administrative procedures. Therefore, convenience - a relative benefit provided by e-government is predicted to be a determinant of citizens' satisfaction.

H5: Convenience has a positive influence on citizens' satisfaction with e-government.

For a long time, the concept of transparency has been closely related to traditional public services, hence, it was pointed that transparency is a crucial condition of a satisfactory relationship between the government and citizens (Meijer, 2013; Birkinshaw, 2006)). As lies in its nature, the provision of e-government would reduce direct human interactions and offer a more open flow of information. Thus, the use of virtual public services with greater transparency can help citizens to cut under table cost and alleviate corruption - a serious problem in some developing countries, which leads to the enhancement of trust and government's accountability. For that reason, the positive impact of transparency on citizens' satisfaction was highlighted in several studies related to online public sector, in which confirmed that when a higher level of transparency is perceived, the greater the likelihood of citizens are going to be satisfied (Kim \& Lee, 2012).

H6: Transparency has a positive influence on citizens' satisfaction with e-government.

\subsection{Research Model}

To achieve the research objectives, two regression equations have been established, corresponding to two models that include/do not include control variables. While Model 1b takes into account the impact of demographic factors on customer satisfaction, model 1a does not.

$$
\begin{aligned}
\text { Model 1a: SAT }= & \beta 0+\beta 1 * \mathrm{EFFi}+\beta 2 * \mathrm{TRUi}+\beta 3 * \mathrm{RELi} \\
& +\beta 4^{*} \mathrm{SUPi}+\beta 5^{*} \mathrm{CONi}+\beta 6^{* \mathrm{TRAi}} \\
& +\varepsilon \mathrm{i} \\
\text { Model 1b: SAT }= & \beta 0+\beta 1 * \mathrm{EFFi}+\beta 2 * \mathrm{TRUi}+\beta 3 * \mathrm{RELi} \\
& +\beta 4^{*} \mathrm{SUPi}+\beta 5^{*} \mathrm{CONi}+\beta 6^{*} \mathrm{TRAi} \\
& +\beta 6^{*} \mathrm{GENi}+\beta 7^{*} \mathrm{AGEi}+\beta 8^{*} \mathrm{EDUi} \\
& +\beta 9^{*} \mathrm{INTi}+\varepsilon \mathrm{i}
\end{aligned}
$$

\subsection{Research Method}

\subsubsection{Sample Selection}

To analyze the factors affecting Vietnamese citizens' satisfaction with e-government services, the selection of the Hanoi residents as a source of the primary data was made due to the city's strategic position and potential. According to the Vietnam Association For Information Processing (2019), Hanoi is the leading city in terms of the human resource infrastructure of the society, which shows that Hanoi people are more able to adopt a new way of governing. Additionally, the city has the highest online public-service efficiency index in the country (Institute of Policy Studies and Media Development, 2018). Therefore, the development of e-government in Hanoi is crucial, and it would be a great lesson for the authorities to be able to apply e-government successfully nationwide.

\subsubsection{Data Collection}

To collect data for our research, we conducted an online questionnaire with citizens living in Hanoi in a time span of five weeks. The questionnaire was designed as two separate sections based on a Likert-scale from 1 to 5, which corresponds to five levels of agreement: strongly disagree, disagree, neutral, agree, strongly agree. The first 
Table 1: Variables Summary

\begin{tabular}{|c|c|c|c|c|}
\hline Variable & Meaning & Determined by & Model & Role \\
\hline SAT & Satisfaction & Overall satisfaction & SAT1 & Dependent variable \\
\hline \multirow[t]{6}{*}{ EFF } & \multirow[t]{6}{*}{ Efficiency } & Web interface & EFF1 & \multirow[t]{6}{*}{ Independent variable } \\
\hline & & Search Engine & EFF2 & \\
\hline & & Customization & EFF3 & \\
\hline & & Appropriate detailed information & EFF4 & \\
\hline & & Fresh information & EFF5 & \\
\hline & & Ease of use & EFF6 & \\
\hline \multirow[t]{3}{*}{ TRU } & \multirow[t]{3}{*}{ Trust } & Secure data & TRU1 & \multirow[t]{3}{*}{ Independent variable } \\
\hline & & Account privacy & TRU2 & \\
\hline & & Information privacy & TRU3 & \\
\hline \multirow[t]{5}{*}{ REL } & \multirow[t]{5}{*}{ Reliability } & Accessibility & REL1 & \multirow[t]{5}{*}{ Independent variable } \\
\hline & & On-time delivery & REL2 & \\
\hline & & Quick forms download & REL3 & \\
\hline & & Browser-system compatibility & REL4 & \\
\hline & & Freeze site & REL5 & \\
\hline \multirow[t]{4}{*}{ SUP } & \multirow[t]{4}{*}{ Citizen Support } & Honesty & SUP1 & \multirow[t]{4}{*}{ Independent variable } \\
\hline & & Quick Support & SUP2 & \\
\hline & & Knowledge & SUP3 & \\
\hline & & Inspires trustworthiness & SUP4 & \\
\hline \multirow[t]{3}{*}{$\mathrm{CON}$} & \multirow[t]{3}{*}{ Convenience } & Access anytime & CON1 & \multirow[t]{3}{*}{ Independent variable } \\
\hline & & Access anywhere & CON2 & \\
\hline & & Convenience to use & CON3 & \\
\hline \multirow[t]{4}{*}{ TRA } & \multirow[t]{4}{*}{ Transparency } & Reduce bribes & TRA1 & \multirow[t]{4}{*}{ Independent variable } \\
\hline & & Reduce cost & TRA2 & \\
\hline & & Reduce bureaucratic process & TRA3 & \\
\hline & & Improve transparency & TRA4 & \\
\hline \multirow[t]{2}{*}{ GEN } & \multirow[t]{2}{*}{ Gender } & Male & \multirow[t]{2}{*}{ GEN } & \multirow[t]{2}{*}{ Control variable } \\
\hline & & Female & & \\
\hline \multirow[t]{3}{*}{ AGE } & \multirow[t]{3}{*}{ Age } & Under 30 & \multirow[t]{3}{*}{ AGE } & \multirow[t]{3}{*}{ Control variable } \\
\hline & & 30 to 50 & & \\
\hline & & Over 50 & & \\
\hline \multirow[t]{3}{*}{ EDU } & \multirow[t]{3}{*}{ Education } & Highschool or lower & EDU & Control variable \\
\hline & & Undergraduate & & \\
\hline & & Postgraduate or higher & & \\
\hline INT & Internet Frequency & Less than once a week & INT & Control variable \\
\hline & & 2 to 7 times a week & & \\
\hline & & More than 7 times a week & & \\
\hline
\end{tabular}


section is research-related questions divided into six parts corresponding to six variables in the research model as well as a question on the overall satisfaction of citizens. The second section contains demographic questions about age, education level, gender, Internet frequency, and their knowledge of e-government services. Overall, there was a total of 1,107 responses, divided into three groups: unaware, known, but not used, and used e-government.

\subsubsection{Data Processing}

The responses are entered into Microsoft Excel where we analyzed and removed illegible responses, including illogical responses (i.e., same scores across all questions, conflicting scores), and citizens who haven't used e-government services. After the analysis in Excel, the total valid observations, now 340, are processed using the following methods: Cronbach's Alpha Test to measure the reliability of the scale; Exploratory Factor Analysis (EFA) to break the data into smaller sets of variables to explore the underlying structure; Descriptive analysis to describe the basic quantitative features of data; Correlation and Regression analysis to evaluate the relationship between variables. In this paper, the first 4 tests run through SPSS 20, and for the Regression analysis, STATA 14 was used.

\section{Results}

\subsection{Reliability Analysis}

To analyze the reliability, the research team conducted a Cronbach's Alpha test. The testing results show that all groups of variables achieved positive results, with appropriate total correlation ( $>0.3)$, and Cronbach's Alpha coefficient reached 0.8 comes close to 1 , indicates a highly reliable measurement scale. However, when evaluating, it is found that: within the Convenience group, the observed variable CON3 has Cronbach's Alpha coefficient if removed $=0.832>0.808$. That means, if we remove the CON3 variable from the model, the reliability of the scale of the Convenience group will improve. In terms of significance, the observed variable CON3 is not extremely important, therefore we proceeded to remove this variable from the model.

\subsection{Exploratory Factor Analysis (EFA)}

Next, the Exploratory Factor Analysis was conducted to validate the constructs, which define the critical factors that explain most of the variance within the data. First, to determine the suitability of the EFA discovery factor for this study, Bartlett and KMO (Kaiser-Meyer-Olkin) tests were used. First the result that $0.5<\mathrm{KMO}$ value $(=0.914)$ $<1.0$ has shown that factor analysis is applicable since it is consistent with the research data set. Second, we consider the necessary condition of the convergent validity, that is, there must be a correlation between observed variables in the same dimension. To ensure this criterion, we examine the result of Bartlett's test by 4800.419 with sig $=0.000$, which means that the data used for factor analysis is appropriate, because there is a clear correlation among the observed variables in the same dimension. Next, five factors are identified, all of them have the Eigenvalues $>1$, therefore they will be retained in the analytical model. Besides, the total variance explained of those components $=67.203 \%>50 \%$, which indicates that the factors converged will explain $67.203 \%$ of the observations' variability. From here, it can be affirmed that the EFA test is guaranteed the requirement of convergent validity.

Additionally, the results also showed that four variables, namely, Access anywhere (CON2), Access anytime (CON1), On-time delivery (REL2), and Honesty (SUP1) are uploaded in more than one component. However, while CON1, CON2 and REL2 must be eliminated from the model, SUP1 will be retained. The rationale is that the first three factors are uploaded in two groups with the difference in the load coefficient of less than 0.3 , which violates the discrimination in rotation matrix, while SUP1 satisfies the condition. Although SUP1 loaded in component 2 and 4 , this variable will belong to the fourth component as it has higher coefficient of factor loading (0.704), compared to that of component 2 (0.363). Except for the three variables, which need to be removed, 21 remaining ones were identified with high factor loading $(>0.5)$, which is statistically significant.

After running EFA for the second time, all the results also proved that the performance of EFA factor analysis was appropriate, and five factors including 21 variables will be retained in the model. As a result of the reliability measurement of the independent variables using Cronbach's Alpha test and exploratory factor analysis, the new research model was developed. This model includes a dependent variable and five independent variables as follows:

$$
\begin{aligned}
\mathrm{SAT}= & \beta 0+\beta 1 * \mathrm{EFFi}+\beta 2 * \mathrm{TRUi}+\beta 3 * \mathrm{RELi}+\beta 4 * \mathrm{SUPi} \\
& +\beta 5^{*} \mathrm{TRAi}+\varepsilon \mathrm{i}
\end{aligned}
$$

Where:

- Efficiency (EFF) is computed by the average of Search Engine, Appropriate detailed information, Web interface, Customization, Ease of use and Fresh information.

- Trust (TRU) is computed by the average of secure data, Account privacy and Information privacy.

- Reliability (REL) is computed by the average of Browser-system compatibility, Freeze site, Quick forms download and Accessibility. 
- Citizens Support (SUP) is computed by the average of Quick Support, Inspires trustworthiness, Honesty and Knowledge.

- Transparency (TRA) is computed by the average of Reduce corruption, Reduce bribes, Reduce cost, transparent transactions.

\subsection{Descriptive Analysis}

Figure 2 represents the descriptive analysis of respondents. While figure (6a) gives an overview of the sample, divided into three categories Unaware, Known, but have not used, and Used the remaining figures (6bcdef) are descriptive analysis of the key factors used to evaluate the satisfaction of the citizens who have already experienced e-government.

Panel (a) represents descriptive statistics of all 1,085 valid survey questionnaires. Among those, only 31.3\% used e-government services. For those who have not used e-government (68.72\%), nearly half of them still do not know that online public services have been exploited and put into operation. However, the results are not too surprising considering the situation: although e-government has been applied in some areas in Vietnam in the past few years, at that time, online public services were mainly for informational purposes, in addition to very limited level 3 and 4 services to support citizens to implement or apply online. In addition, until December 9th, 2019, the National Public Service Portal has just been officially opened and on the way to start promoting online public services to serve the needs of the people. Therefore, citizens do not have much time to learn and use e-government.

Panel (b) shows the difference in satisfaction level between the youngest group (under 30) and the oldest group (over 50), in a decreasing trend with all six observed variables from the Efficiency component. If the youngest group usually rates those factors at 3.5 and above and the group from 30 to 50-year-old is at around 3.5, the satisfaction of the over 50-year-old group only fluctuates around 2.9. Also, not out of this trend, in Panel (c) people under 30 give an average rating of more than 3.5 for all three factors of Trust, while people aged between 30 and 50 give an average rating of over 3 and people over 50 only give a score of 2.5. Similarly, the average score for Satisfaction of respondents under 30 is approximately 3.8 , while the score for those aged 30 to 50 are reduced to less than 3.7 and for people above 50 is around 3.3, as shown in Panel (e).

However, the only exception to the trend of diminishing satisfaction by age is shown in Panel (d), when it comes to Citizen Support. Particularly with two factors: Quick Support and Honesty, the satisfaction level of people in the age of 30 to 50 is a little higher than the those under 30 years old; while the Inspires trustworthiness factor was assessed equally between those two groups of respondents. Other than that, people over 50 still tend to have the lowest satisfaction with e-Government. This can be explained by the reason that younger people are more adept at using the Internet or information technology tools, thus easier to adapt to e-government. Moreover, younger audiences will often be more comfortable adapting to new technologies than the rest, so they find it easier to use online public services, which in turn suggests a greater level of satisfaction.

Finally, Panel (f) shows the correlation between the average satisfaction score and the education level of the respondents. The results show a noticeable difference between post-graduate respondents and the remaining two groups. While those with postgraduate education only had an average satisfaction score of 3.6, the group of people who are in High school or lower or have an Undergraduate education showed a higher satisfaction level, at 3.74., and 3.79 respectively. From the above results, a preliminary cause predicted by the authors is that people with a higher level of education will often have higher expectation on the quality of e-government systems, which makes them more rigorous when assessing the satisfaction.

\subsection{Correlation Analysis}

To evaluate the correlation between variables in the model, the Pearson test was performed. In general, between five independent variables and the dependent variable Satisfaction there is a linearly positive relationship. This is confirmed by sig $=0.000$, meaning the correlation between them is statistically significant, and the Pearson Correlation coefficient is positive ( $r>0)$ and ranges from 0.469 to 0.606 . As the correlation coefficient $r$ in the range of 0.1 to 0.3 indicates a small correlation, the range of 0.3 to 0.5 indicates the average correlation and the coefficient above 0.5 indicates a large correlation. Therefore, the Efficiency variable is determined as having the largest and strongest correlation with Satisfaction $(r=0.606)$. In contrast, the Trust variable has the least relation with the remaining variables, having $r$ $=0.408$, but still in the average correlation level.

Regarding the correlation between the independent variables, there are several variables that are quite strongly correlated with each other, including the pairs of Efficiency with Reliability, Efficiency with Citizen Support and Citizen Support with Trust ( $r>0.5)$. Therefore, multi-collinearity can occur between these pairs of variables. To test this question, we will evaluate the VIF coefficient when regression analysis in the next section.

\subsection{Regression Analysis}

In model (1a), the Adjusted $\mathrm{R}^{2}$ value $=0.4696$ shows that the independent variables in the regression model affected 
Thuy Thu NGUYEN, Duc Manh PHAN, Anh Ha LE, Lan Thi Ngoc NGUYEN /

(a) Demographic

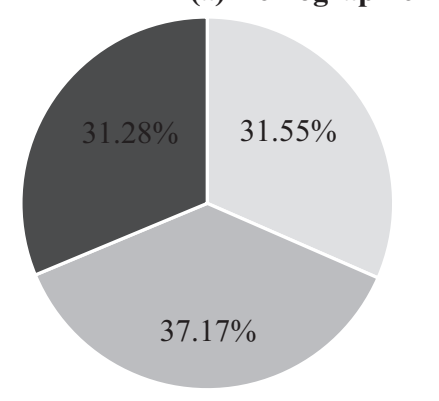

Unknown

Known but haven't used

- Used

b)

\section{Efficiency with ages}

Web interface

Search engine

Customization

Appropriate detailed information

Fresh information

Ease of use
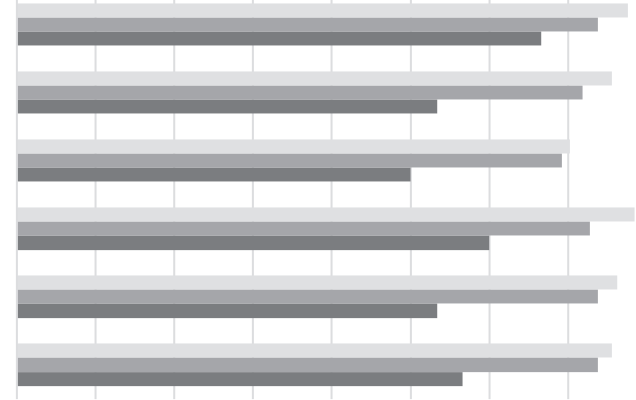

$\begin{array}{llllllllll}0 & 0.5 & 1 & 1.5 & 2 & 2.5 & 3 & 3.5 & 4 & 4.5\end{array}$

Under $30 \quad 30$ to $50 \quad$ Over 50

(c) Trust with ages

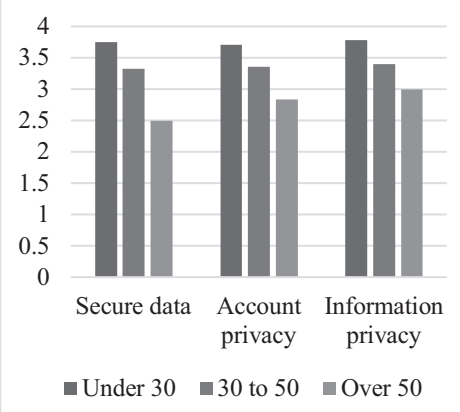

(e) Satisfaction with ages

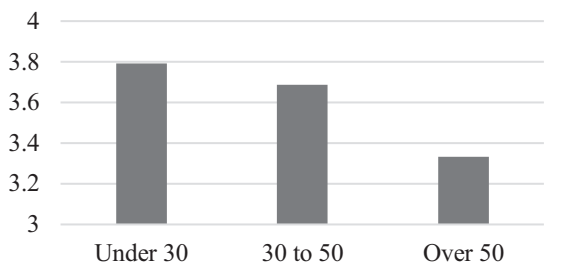

(d) Citizens Support with ages

Inspires trustworthiness

Knowledge

Quick Support

Honesty

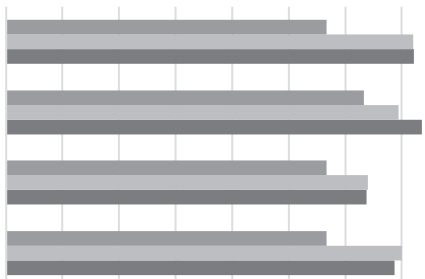

$\begin{array}{lllllllll}0 & 0.5 & 1 & 1.5 & 2 & 2.5 & 3 & 3.5 & 4\end{array}$

- Over $50 \quad \square 30$ to $50 \quad \square$ Under 30

(f) Satisfaction with educational levels

Postgraduate

Undergraduate

High school or lower

$\begin{array}{lllllll}3.5 & 3.55 & 3.6 & 3.65 & 3.7 & 3.75 & 3.8\end{array}$

Figure 2: Descriptive statistics of respondents 
$46.96 \%$ of the variation of the dependent variable, while the remaining $53.04 \%$ is due to non-model variables and random errors. This level of influence is acceptable, especially in the context that e-government is not a prevalent concept investigated in many scientific studies in Vietnam, thus there still are determinants of the satisfaction of Vietnamese citizens that are unrevealed.

Furthermore, it can be seen that except for Trust - a variable that is not statistically significant in the model (sig $=0.289>0.05$ ), the remaining variables are statistically significant at the $99 \%(\mathrm{sig}<0.01)$ and $95 \%$ confidence level $($ sig $<0.05)$. Specifically, the Efficiency variable has the coefficients $b 1=0.288$, showing that Efficiency has a strong and positive impact on Satisfaction, with a $99 \%$ confidence level (sig=0.000). Similarly, Reliability, Citizens Support and Transparency have the coefficients $\mathrm{b} 3=0.158$ ( $\mathrm{sig}=0.002)$, b4 $=0.269(\mathrm{sig}=0.000)($ at $99 \%$ confidence level $)$ and b5 $=0.114$ ( $\operatorname{sig}=0.011$ ) (at 95\% confidence level) respectively, which also confirm the significant and positive impact of those independent variables on Satisfaction. Specifically, when the Efficiency variable increases by 1 unit (holding other factors constant), the citizens' satisfaction increases by 0.288 units, the same for the Reliability and Citizen Support and Transparency variables. In summary, the results indicate that the 4 independent variables are significant in the model and are all related to the Citizens' Satisfaction, except for Trust.

As Standardized Beta value is used to assess the importance of independent variables, to find out the influence of each variable on Citizens' Satisfaction, the regression result illustrates that Satisfaction is mostly affected by the factor Efficiency $(\mathrm{b} 1=0.288)$, and then the impact will be in descending order as follows: Citizens Support $(\mathrm{b} 4=0.269)$, Reliability $(\mathrm{b} 3=0.158)$ and Transparency (b5=0.114). Generally, as the Betas have positive values, it can be said that as perceived Efficiency, Reliability, Citizens Support and Transparency increase, Citizens' Satisfaction of e-government will rise as well. In conclusion, excluding Hypothesis 2, which affirms the positive influence of Trust on citizens' satisfaction, Hypothesis 1, 3, 4 and 6 are supported.

Model (1b) summarizes the results of multiple linear regressions with the addition of demographic variables. The results suggest, that except for Trust, the other factors, namely, Efficiency, Reliability, Citizen Support, and Transparency are significant predictors of e-government satisfaction. Overall, all the factors in model (1b) explain $46.59 \%$ of the variation of the dependent variable (Adjusted $\mathrm{R}$ square $=0.4659$ ), while the remaining $53.41 \%$ is due to non-model variables and random errors. Similar to model (1a), with the exception of Trust - a variable that is not statistically significant in the model at the $90 \%$ confidence level (sig. > 0.1), the remaining independent variables have a statistically significant impact on Satisfaction at the $99 \%$ confidence level (sig. <0.01). Specifically, Efficiency has a beta coefficient of 0.278 at $99 \%$ confidence level, suggesting that an increase of 1-unit score in Efficiency increases Satisfaction score by 0.278 , all else equal. Citizen Support (b4 $=0.269)$, Reliability ( $33=0.158)$, and Transparency $(b 5=0.114)$ also shows the same positive relationship with

Table 3: Summary of regression models

\begin{tabular}{|c|c|c|c|c|c|c|}
\hline \multirow[b]{2}{*}{ Variables } & \multicolumn{3}{|c|}{ (1a) } & \multicolumn{3}{|c|}{ (1b) } \\
\hline & $\begin{array}{c}\beta \\
\text { Unstandardized }\end{array}$ & $\begin{array}{c}\beta \\
\text { Standardized }\end{array}$ & $\begin{array}{l}\text { Standard } \\
\text { Error }\end{array}$ & $\begin{array}{c}\beta \mid \\
\text { Unstandardized }\end{array}$ & $\begin{array}{c}\beta \\
\text { Standardized }\end{array}$ & $\begin{array}{l}\text { Standard } \\
\text { Error }\end{array}$ \\
\hline Efficiency & $0.288^{* * *}$ & .287 & 0.0554 & $0.278^{* * *}$ & .278 & 0.0570 \\
\hline Trust & 0.047 & .050 & 0.0442 & 0.061 & .065 & 0.0459 \\
\hline Reliability & $0.158^{* * *}$ & .154 & 0.0507 & $0.165^{* * *}$ & .161 & 0.0514 \\
\hline Citizen Support & $0.269^{* * *}$ & .267 & 0.0539 & $0.262^{* * *}$ & .259 & 0.0556 \\
\hline Transparency & $0.114^{* *}$ & .115 & 0.0448 & $0.118^{* * *}$ & .119 & 0.0453 \\
\hline Gender & & & & -0.059 & -.034 & 0.0720 \\
\hline Age & & & & 0.057 & .040 & 0.0639 \\
\hline Education & & & & 0.002 & .001 & 0.0662 \\
\hline $\begin{array}{l}\text { Internet } \\
\text { Frequency }\end{array}$ & & & & 0.034 & .018 & 0.0757 \\
\hline Constant & $0.530^{* * *}$ & & 0.2024 & 0.339 & & 0.3392 \\
\hline Observations & \multicolumn{3}{|c|}{340} & \multicolumn{3}{|c|}{340} \\
\hline $\mathrm{R}^{2}$ & \multicolumn{3}{|c|}{0.4774} & \multicolumn{3}{|c|}{0.4800} \\
\hline Adjusted $\mathrm{R}^{2}$ & \multicolumn{3}{|c|}{0.4696} & \multicolumn{3}{|c|}{0.4659} \\
\hline
\end{tabular}


E-government satisfaction at $99 \%$ confidence level. In other words, since the beta coefficients of independent variables all hold positive values, we expect e-government satisfaction to be positively influenced by those 4 variables.

In addition, considering the impact level of those four significant variables, the standardized coefficient shows that the Efficiency variable has the greatest impact on citizens' satisfaction $(\mathrm{b} 1=0.0570)$. Also, with $\mathrm{b} 4=0.0556>\mathrm{b} 3$ $=0.0514>\mathrm{b} 5=0.0453$, we concluded that the degree of impact on Satisfaction of the remaining three variables in descending order is as follows: Citizen Support, Reliability and Transparency.

Regarding control variables, their influence on E-Government satisfaction is not statistically significant at the $90 \%$ confidence level. Although the positive relationship between Age and Satisfaction $(\mathrm{b} 7=0.057)$ is indicated, as well as Educational Level $(\mathrm{b} 8=0.002)$ and Internet Frequency ( $\mathrm{b} 9=0.034)$, the effect of these variables on citizens' satisfaction is not statistically significant with $90 \%$ confidence level (sig> 0.1). Similarly, although Gender has an unstandardized coefficient b6 $=-0.059$, meaning that women have lower e-government satisfaction, this variable is not statistically significant (sig $>0.1$ ). In general, all control variables do not have a significant impact on citizens' Satisfaction.

In conclusion, in model (1b), Hypothesis 1, 3, 4, 6 are supported; Hypothesis 2 is excluded. Additionally, it is identified that the control variables measuring graphic factors have no significant impact on Citizens' Satisfaction, thus implies the existence of control variables is unnecessary in the final research model. Furthermore, compared to model (1a), the value of Adjusted R-square of model (1b) is lower, which means model (1a) has a better capacity to explain the variance of the dependent variable. As a result, the use of model (1a) is the preferred option. From the entire analysis above, the final research model can be written as:

$$
\begin{aligned}
\mathrm{SAT}= & 0.53+0.288 * \mathrm{EFF}+0.158 * \mathrm{REL}+0.269 * \mathrm{SUP} \\
& +0.114 * \mathrm{TRA}+\mathrm{e}
\end{aligned}
$$

\section{Conclusions and Recommendations}

\subsection{Conclusion}

The main objectives of this research are to identify the determinants of e-government satisfaction in Hanoi, Vietnam, and assess their impact. We leveraged past studies on satisfaction in different contexts and arrived at six external variables that are of particular relevance to e-government satisfaction (i.e., efficiency, trust, reliability, convenience, citizen support, and transparency) as well as four control variables (i.e., age, gender, education level, and internet frequency). The results demonstrated that, apart from
Convenience and Trust, four factors - Efficiency, Reliability, Citizens support and Transparency - are important measures of system quality, information quality, service quality and relative benefits of e-government, which in turn positively and significantly impact citizens' satisfaction with the online public services. In particular, the Efficiency variable has the most influence on Satisfaction, and the level of impact on dependent variable decreases in the following order: Citizen Support, Reliability and Transparency.

\subsection{Recommendations}

Based on the research results, Efficiency is considered by the citizens as the most significant factor affecting their satisfaction with e-government. To boost citizens' satisfaction with e-government, the Government needs to improve the individualization of e-government. The results show that citizens do not appreciate the ability to customize information (i.e., marking frequently used forms) on e-government websites. Furthermore, because Citizen Support is the second most important factor in determining citizens' satisfaction with e-government, the speed of responding to comments or feedback from e-government is the issue that needs the most improvement. In order to speed up the process of receiving and responding to citizens' requests, we suggest applying artificial intelligence (AI) technology to the e-government system. Specifically, the Government can consider using Chatbots or virtual assistants and a frequency asked questions (FAQs) section on the Government's website, especially on the National Public Service Portal to support citizens. The availability of these services anytime anywhere will help the Government to minimize difficulties in using the system. Secondly, based on the survey responses, the e-Government support staff currently do not give them the feeling of trust and solve the problem yet quickly. The Government should provide training to improve the qualifications and attitudes of support staff. We believe that a citizen-centric approach will greatly improve e-government experience and increase satisfaction.

\subsection{Limitations and Future Research Directions}

Firstly, in terms of subjects, this research only focused on examining the topic of e-government from the perspective of the citizens, that is, type $\mathrm{G} 2 \mathrm{C}$ - one of the four subjects that e-government aims at. Therefore, this topic still has room for other works to research about other objects type: G2E, G2B, or G2G. In addition, future studies also need to be careful when generalizing and applying the results of this research to the three objects mentioned above. Secondly, in terms of location, this research is only implemented in Hanoi, so it cannot give the most accurate assessment and prediction for all Vietnamese citizens. Thirdly, this research is conducted 
within a short time, while the psychology and needs of users often change. Therefore, to be able to overcome these disadvantages and effectively grasp those factors, studies based on long-term survey data and panel data are necessary.

\section{References}

Bhattacharya, D., Gulla, U., \& Gupta, M. P. (2012). E-service quality model for Indian government portals: Citizens' perspective. Journal of Enterprise Information Management, 25(3), 246-271.

Birkinshaw, P. (2006). Freedom of Information and Openness: Fundamental Human Rights? Administrative Law Review, 58(1), 177-218. www.jstor.org/stable/40712007

Cardozo, R. N. (1965). An Experimental Study of Customer Effort, Expectation, and Satisfaction. Journal of Marketing Research, 2(3), 244-249.

Carter, L., \& Bélanger, F. (2005). The utilization of e-government services: Citizen trust, innovation and acceptance factors. Information Systems Journal, 15(1), 5-25.

Chan, F., Thong, J., Venkatesh, V., Brown, S., Hu, P., \& Tam, K. (2010). Modeling Citizen Satisfaction with Mandatory Adoption of an E-Government Technology. Journal of the Association for Information Systems, 11(10), 519-549.

Chen, J. V., Jubilado, R. J. M., Capistrano, E. P. S., \& Yen, D. C. (2015). Factors affecting online tax filing - An application of the IS Success Model and trust theory. Computers in Human Behavior, 43, 251-262.

Vietnam E-government Portal. (2019). Vietnam ICT index 2019. Retrieved June 7, 2020, from: http://egov. chinhphu.vn/ket-qua-xep-hang-vietnam-ict-index-2019-anewsdetails-37749-186186.html

Collier, J. E., \& Sherrell, D. L. (2010). Examining the influence of control and convenience in a self-service setting. Journal of the Academy of Marketing Science, 38(4), 490-509.

Day (1984). Modeling Choices Among Alternative Responses to Dissatisfaction. In NA - Advances in Consumer Research, Volume 11 (pp. 496-499), Thomas C. Kinnear (ed.), Provo, UT: Association for Consumer Research.

Delone, W., \& McLean, E. (2003). The DeLone and McLean Model of Information Systems Success: A Ten-Year Update. Journal of Management Information Systems, 19(4), 9-30.

Giao, H. N. K. (2020). Customer Satisfaction at Tiki.vn E-Commerce Platform. Journal of Asian Finance, Economics, and Business, 7(4), 173-183. https://doi.org/10.13106/jafeb.2020.vol7. no4.173

Gilbert, D., Balestrini, P., \& Littleboy, D. (2004). Barriers and benefits in the adoption of e-government. International Journal of Public Sector Management, 17(4), 286-301.

Hujran, O. A., Aloudat, A., \& Altarawneh, I. (2013, April 1). Factors Influencing Citizen Adoption of E-Government in Developing Countries: The Case of Jordan. International Journal of Technology and Human Interaction, 9(2), 1-19.
Jiang, J. J., Klein, G., \& Crampton, S. M. (2000). A Note on SERVQUAL Reliability and Validity in Information System Service Quality Measurement. Decision Sciences, 31(3), 725-744.

Kim, S., \& Lee, J. (2012). E-participation, transparency, and trust in local government. Public Administration Review, 72(6), 819828.

Lin, H.-F. (2007). The Impact of Website Quality Dimensions on Customer Satisfaction in the B2C E-commerce Context. Total Quality Management \& Business Excellence, 18(4), 363-378.

Livari, J. (2005). An empirical test of the DeLone-McLean model of information system success. ACM SIGMIS Database: the DATABASE for Advances in Information Systems, 36(2), 8-27.

Loan, N. (2020). Business satisfaction of online tax filing service in Thai Nguyen (Thai Nguyen University of EconomicsFinance). Retrieved from: https://drive.google.com/drive/u/1/ folders/15erD2Z4PvtwPpQ83D187oUltg8pD_ohD

Meijer, A. (2013). Understanding the complex dynamics of transparency. Public Administration Review, 73(3), 429-439.

Meuter, M. L., Ostrom, A. L., Roundtree, R. I., \& Bitner, M. J. (2000). Self-service technologies: Understanding customer satisfaction with technology-based service encounters. Journal of Marketing, 64(3), 50-64.

Miyazaki, A. D., \& Fernandez, A. (2001). Consumer Perceptions of Privacy and Security Risks for Online Shopping. Journal of Consumer Affairs, 35(1), 27-44.

Mosahab, R., Mahamad, O., \& Ramayah, T. (2010). Service Quality, Customer Satisfaction and Loyalty: A Test of Mediation. International Business Research, 3(4), 72. DOI:10.5539/ibr. v3n $4 \mathrm{p} 72$

Nguyen, T. (2017). Customer satisfaction with quality of automated customs clearance service VNACCS/VCIS in Danang (Danang University of Economics). Retrieved from: https://drive.google. com/drive/u/1/folders/15erD2Z4PvtwPpQ83D187oUltg8pD_ ohD

Oliver, R. L. (1977). Effect of expectation and disconfirmation on post-exposure product evaluations: An alternative interpretation. Journal of Applied Psychology, 62(4), 480-486.

Papadomichelaki, X., \& Mentzas, G. (2012). e-GovQual: A multiple-item scale for assessing e-government service quality. Government Information Quarterly, 29(1), 98-109.

Parasuraman, A., Berry, L. L., \& Zeithaml, V. A. (1991). Refinement and reassessment of the SERVQUAL scale. Journal of Retailing, 67(4), 420-450.

Pitt, L. F., Watson, R. T., \& Kavan, C. B. (1995). Service Quality: A Measure of Information Systems Effectiveness. MIS Quarterly, 19(2), 173-187.

Rust, \& Oliver, R. L. (1994). Service quality: Insights and managerial implications from the frontier. In: Service Quality: New Directions in Theory and Practice (pp. 1-19). Thousand Oaks, CA: Sage Publications. http://dx.doi. org/10.4135/9781452229102.n1 
Santos, J. (2003). E-service quality: A model of virtual service quality dimensions. Managing Service Quality: An International Journal, 13(3), 233-246.

Seetharaman, A., Saravanan, A. S., Patwa, N., \& Bey, J. M. (2017). The Impact of Property Management Services on Tenants' Satisfaction with Industrial Buildings. Journal of Asian Finance, Economics and Business, 4(3), 57-73. http://dx.doi. org/10.13106/jafeb.2017.vol4.no3.57

Szymanski, D. M., \& Henard, D. H. (2001). Customer satisfaction: A meta-analysis of the empirical evidence. Journal of the Academy of Marketing Science, 29(1), 16-35.

United Nations. (2018). United Nations E-Government Survey 2018: Gearing E-Government to Support Transformation towards Sustainable and Resilient Societies. Retrieved June 7, 2020, from: https://www.un-ilibrary.org/democracy-andgovernance/united-nations-egovernment-survey-2018_ d54b9179-en

Usman, H. (2015). Customers trust on Islamic banks in Indonesia. Journal of Asian Finance, Economics, and Business, 2(1), 5-13. https://doi.org/10.13106/jafeb.2015.vol2. no1.5.

Van Dyke, T. P., Kappelman, L. A., \& Prybutok, V. R. (1997). Measuring Information Systems Service Quality: Concerns on the Use of the SERVQUAL Questionnaire. MIS Quarterly, 21(2), 195-208.

Venkatesh, V., Thong, J. Y. L., Chan, F. K. Y., Hu, P. J.-H., \& Brown, S. A. (2011). Extending the two-stage information systems continuance model: Incorporating UTAUT predictors and the role of context: Context, expectations and IS continuance. Information Systems Journal, 21(6), 27-555.

Verdegem, P., \& Verleye, G. (2009). User-centered E-Government in practice: A comprehensive model for measuring user satisfaction. Government Information Quarterly, 26(3), 487-497.

Warkentin, M., Gefen, D., Pavlou, P., \& Rose, G. M.(2002). Encouraging Citizen Adoption of e Government by Building Trust. Electronic Markets, 12(3), 157-162.

Welch, E. W. (2004). Linking Citizen Satisfaction with E-Government and Trust in Government. Journal of Public Administration Research and Theory, 15(3), 371-391.

Westbrook, R. A., \& Reilly, M. D. (1983). Value-percept disparity: an alternative to the disconfirmation of expectations theory of consumer satisfaction. ACR North American Advances, 10(1), 256-261. 